\title{
Age-related differences in reporting of drug-associated liver injury: Data-mining of the WHO Safety Report Database
}

\author{
By
}

Christine M. Hunt

\begin{abstract}
A Master's Paper submitted to the faculty of the University of North Carolina at Chapel Hill in partial fulfillment of the requirements for the degree of Master of Public Health in the Public Health Leadership Program
\end{abstract}

Chapel Hill

Adviser

Date

Second Reader

Date 


\section{Table of Contents}

Introduction

Research Paper

Abstract

Introduction

Methods

Results

Discussion

References

Tables

Leadership reflections p. 3-6

p. 7-52

p. 8-9

p. $10-13$

p. $13-17$

p. $17-19$

p. $19-24$

p. $25-43$

p. $44-52$

p. $53-56$ 


\section{Introduction}

\section{Structure of the Paper}

This paper presents a data mining analysis of World Health Organization drug adverse event case reports, to examine age-related differences in liver event reporting in children, adults and the elderly. These reporting differences were then compared to established aging-related physiologic differences, and drug-specific physicochemical characteristics to generate hypotheses on hepatotoxicity mechanisms which might affect a targeted age group.

The paper includes three parts: 1 . an introduction to the analytic approach, 2. a research paper in manuscript form (as a planned submission to Pharmacoepidemiology and Drug Safety), and 3. leadership reflections.

\section{Analytic Approach}

Over the past 15 years, international regulatory and pharmacovigilance experts have tested and established preferred data mining tools and uses in publicly available global drug safety datasets (Almenoff 2005). Data mining uses Bayesian and empirical Bayesian methods to adjust for variability in event reports, even with small numbers. Disproportionality analyses then identify drugadverse event pairs with unexpectedly high reporting as a potential "signal", using empirically tested thresholds. Current data mining analyses frequently use the high specificity disproportionality-based signal detection method of empirical Bayes multi-item gamma Poisson shrinker (MGPS), which provides a quantitative measure of 
"expectedness" to drug adverse event reports (Almenoff 2006). This quantitative "signal score" is then further analyzed with medical case review, disease biology, drug interactions and other factors and provides the theoretical foundation for future investigations to assess the biologic plausibility of a causal relationship of the drugadverse event pair.

With small adverse event counts, MGPS precision is diminished, so the program decreases the observed to expected ratios to minimize false-positive signals. The MGPS software generally stratifies data by event categories, with 40 year-, 11 age group-, and 3 gender-categories (male, female and unknown) to further adjust background differences in relative reporting. This adjustment decreases potential confounding by variability in prescribing practice and associations with a stratum variable. After Bayesian smoothing, empiric Bayes geometric mean (EBGM) values demonstrate the strength of the association of the drug and the adverse event pair to display the relative reporting rates. An EBGM of 5 indicates that the drug-adverse event combination is reported at a 5 -fold higher frequency than expected reporting frequency computed assuming that there is no association between the drug and the adverse event. Empirically, an EBGM >2 for a drug-adverse event combination is interpreted as a significantly increased reporting frequency (a positive association between the drug and the adverse event), while an EBGM $\leq 1$ is interpreted as either no association or a negative association between the drug and the adverse event. The $90 \%$ confidence intervals [lower limit (EB05) and upper limit (EB95)] are calculated to assess differences in reporting frequency. To examine reporting differences, the EB05 and EB95 intervals are compared for an overlap, as performed in the current study. Stratification enables 
analyses of data subsets, including age groups, over time.

Data mining is particularly useful for generating hypotheses, which must be further tested using alternate data sources, including careful medical case review, clinical or epidemiological observational studies, and in-vitro or in-vivo experiments. Data mining's key strength is its ability to sort a large number of drug-adverse event pairs and provide a numeric score of how frequently event pairs are observed, relative to that which is expected in the database background.

It's easy to interpret the results, as the magnitude of this signal score shows the strength of the association with confidence limits or $p$-values. The shortcomings of safety data mining are the likely underreporting of adverse events in global safety databases, potential reporting biases, and data incompleteness (even for serious or fatal events). Causality cannot be inferred with data mining analyses, even when using data mining methodology of high specificity. At minimum, additional medical review and assessment of biologic plausibility is needed. Therefore, even data mining analyses with a high signal score are reported using terms, such as "observed reporting relationship" and "possible causality" (Almenoff 2005).

Data mining is now routinely performed in drug safety (Rivkees 2010). FDA examines global datasets to identify drug adverse event associations between drugs of similar structure, indication, or of similar structure and differing indications to generate hypotheses about potential new drug adverse events (Almenoff 2006). New "signals" are then interrogated through careful medical review. The current study has examined new liver safety "signals" by age group, to compare with drug physicochemical 
properties and aging-specific differences in physiology, to generate hypotheses on the mechanisms contributing to drug toxicity susceptibility with development and aging. 
Age-related differences in reporting of drug-associated liver injury: Data-mining of the WHO Safety Report Database

Short title: Drug-associated liver injury in young and old (39 characters; $\leq 45$ )

Christine M. Hunt, Nancy A. Yuen, Heide A. Stirnadel-Farrant, Ayako Suzuki

Key Words: hepatotoxicity, drug-induced liver injury, aging, pediatric, data-mining

Abbreviations: drug-induced liver injury (DILI), Empirical Bayes Geometric Mean (EBGM), Empirical Bayes Geometric Mean of the relative reporting ratio with $90 \%$ confidence interval (EB05 and EB95), individual case safety report (ICSR), Medical Dictionary for Regulatory Activity (MedDRA), World Health Organization (WHO)

Authors' contributions (all authors can attest to the intellectual content of the paper):

Christine M. Hunt: study development, implementation, manuscript preparation

Nancy A. Yuen: study development, implementation, manuscript review

Heide A. Stirnadel-Farrant: study development, implementation, manuscript review

Ayako Suzuki: study development, implementation, manuscript preparation 
Abstract $(254$ words, 250 words $=$ max for Pharmacoepid \& Drug Safety)

Background/aims: Children, adults and the elderly exhibit differing frequency and manifestations of drug-induced liver injury, which may be due to physiological changes associated with development and/or aging. WHO Safety Report Database data-mining analyses assessed the impact of age on liver event reporting frequency with different phenotypes.

Methods: 236 drugs associated with hepatotoxicity in the WHO Safety Report Database were evaluated using the Empirical Bayes Geometric Mean (EBGM) of the relative reporting ratio with $90 \%$ confidence interval (EB05 and EB95) calculated for 3 different age groups, $0-17,18-64$, and $\geq 65$ years (or elderly), for overall, serious (acute liver failure), hepatocellular, and cholestatic liver injury.

Results: Overall, cases of age $0-17,18-64$, and 65 years or older comprised $6 \%, 62 \%$, and $32 \%$ of liver event reports. Acute liver failure and hepatocellular injury were more frequently reported among children compared to adults and the elderly while reports with cholestatic injury were more frequent among the elderly $(p<0.00001)$. Twenty-nine drugs, including anti-retrovirals, CNS agents, and antimetabolites, were associated with significantly higher reporting frequency among children vs. others, while 10 drugs were associated with significantly higher reporting frequency among the elderly. Regarding drug characteristics, a potential to cause mitochondrial dysfunction was more prevalent among the drugs with increased pediatric reporting frequency while high lipophilicity and biliary excretion were more common among the drugs associated with higher reporting frequency in the elderly. 
Conclusion: Our analysis identified age-specific phenotypes in reported liver events and potential drug properties associated with age-specific hepatotoxicity. Further analyses are warranted to better understand potential age-specific susceptibility. 


\section{Introduction}

In the United States, drug-induced liver injury is the leading cause of death from acute liver failure in adults (Ostapowitz 2002). Older adults (age 60 and over) exhibit generally similar outcomes to younger adults (Schiødt 2009). In contrast, children with drug-induced acute liver failure can exhibit much poorer outcomes than adults, with a $73 \%$ one year mortality after liver transplantation for antiepileptic-induced liver failure (Mindikoglu 2009). Fortunately, children rarely exhibit drug-induced acute liver failure, which accounts for only $20 \%$ of acute liver failure events (Murray 2008), and is primarily associated with acetaminophen, anti-epileptics and anti-tuberculosis drugs (Squires 2006, Molleston 2011). While children ( $<18$ years) comprise $26 \%$ of the US population, they account for only $7 \%$ of reported serious drug adverse events overall (Moore 2007), with hepatic events accounting for only $1 \%$ of reported pediatric adverse drug events globally (Ferrajolo 2010).

Overall, serious drug adverse events account for $3-6 \%$ of hospital admissions (Moore 2007). The average ambulatory Medicare patient consumes 4 medications or more daily (Gurwitz 2003), and most (63\%) use complementary and alternative medications (Cheung 2007), contributing to adverse drug reactions (Gurwitz 2003). While the elderly ( $\geq 65$ years) constitute only $13 \%$ of the US population (Moore 2007), they account for approximately one third of serious adverse drug reports. The US elderly population is growing rapidly and will double by 2050 (US Census Bureau), so identifying and addressing risk factors for drug-induced liver injury in this vulnerable population is a key concern. 
Nearly half (46\%) of drug-induced liver injury events in the large, prospective Spanish Drug-induced Liver Injury Registry occurred in those over age 60, with amoxicillin/clavulanate frequently implicated. Amoxicillin/clavulanate is the most common cause of drug-induced liver injury in many countries, accounting for approximately $10 \%$ of cases (Andrade 2005 , Chalasani 2008 ) and up to $57 \%$ of cases of antibiotic-induced jaundice (Hussaini 2007). The incidence of drug-induced liver injury with amoxicillin/clavulanate increases 3-fold with age, multiple prescriptions, longer treatment duration (Garcia Rodriguez 1996) and specific HLA Class I and II alleles (Lucena 2011), with cholestatic injury most common in the elderly (Lucena 2009).

Most drugs $(77 \%)$ causing drug-induced liver injury or acute liver failure are administered at daily doses of $50 \mathrm{mg}$ or higher (Lucena 2009) and undergo significant hepatic metabolism (Lammert 2010). Furthermore, $85 \%$ or more of drugs with both a high daily dose $(\geq 100 \mathrm{mg}$ ) and high lipophilicity (with octanol-water partition coefficient, or $\log P \geq 3$ ) are significantly associated with hepatotoxicity (Chen 2013).

Age and development substantially influence drug metabolism (Kearns 2003, Klotz 2009), inflammation and regeneration (Hohensinner 2011, Grolleau-Julius 2010, Chen 2010). Children exhibit age-related changes in drug absorption, distribution, metabolism and excretion, which are most marked in infancy and are generally similar to adults in children over age 8 (Kearns 2003). Mitochondrial DNA polymerase gamma gene (POLG1) polymorphisms frequently manifest in the first few years of life and contribute to valproate hepatotoxicity (McFarland 2008, Squires 2006). When coadministered with other anti-epileptics, valproate hepatotoxicity results in a 1 in 550 rate of acute liver failure in those under age 2 (Murray 2008), in contrast to 1 in 80,000 
rate of significant hepatotoxicity in adults (Dealberto 2007). Children may be more susceptible to medications causing mitochondrial injury and hepatotoxicity, in comparison to adults and the elderly.

Liver mass, regeneration, and hepatic blood flow decrease with normal aging, resulting in lower first pass clearance of select drugs in the elderly (Klotz 2009, Schmucker 2011), although the activity of most Phase I and II enzymes are unaffected by aging (Klotz 2009, Hunt 1990, Hunt 1992, Schwartz 2006, Schmucker 2011). However, inter-individual pharmacokinetic variability can increase due to aging-related changes in drug disposition in the elderly with increasing body fat or delayed gastric emptying, decreased renal blood flow and excretion (Klotz 2009), and decreased mitochondrial function (Lo'pez-Lluch 2008). A moderate decline in biliary function, with decreased bile flow and bile acid secretion, and in liver regeneration following injury is observed in the elderly (Schmucker 2011). Aging-related relative immune deficiencies and increased autoimmunity are associated with shortening telomeres, increasing CD28- T cells contributing to auto-reactivity, DNA hypomethylation, and alterations in histone acetylation (Hohensinner 2011, Grolleau-Julius 2010). Drugs of high lipophilicity or exhibiting high first pass clearance, or those undergoing biliary excretion or resulting in autoimmune injury, may more commonly result in hepatotoxicity in the elderly, due to the aforementioned aging-related physiologic changes.

It's essential to examine the effect of aging on drug-induced liver injury manifestation and frequency in children and the elderly to avoid the risk of severe and unpredictable injury in these vulnerable populations. Drug-induced liver injury occurs infrequently (Sgro 2002, de Abajo 2004), so large databases are needed to examine 
risk factors. The World Health Organization (WHO) Safety Report Database is a global database of adverse drug reactions that includes millions of reports (Lindquist 2008). To assess the impact of age on liver event reporting frequency and phenotype, two hundred thirty six drugs associated with hepatotoxicity were evaluated with data-mining analyses in the WHO Safety Report Database. Drugs associated with a higher reporting frequency by age group were further analyzed by physicochemical properties, daily dose, metabolism, transport, immunologic, or other attributes or liabilities by age group. We hypothesized that mitochondrial dysfunction could be more common in drugs associated with pediatric hepatotoxicity (due to inborn mitochondrial genetic defects), and that drugs of highly lipophilicity, dose, high first pass clearance, biliary excretion, or which inhibit bile acid efflux (e.g. through the bile salt export pump or multidrug resistance associated proteins $-2,-3$, and -4 ) could be more highly represented in the elderly. The findings of this data-mining analysis further refined the theoretical foundation for future investigations on aging-related susceptibilities to hepatotoxicity. Identification of aging-related susceptibilities to targeted drug properties will in turn help to avoid or minimize these features in the design of new drugs for these age groups. In addition, the identification of specific drugs associated with hepatotoxicity in targeted age group will enable clinicians to select safer alternatives.

\section{Methods}

Study Design: This is a descriptive data mining analysis using a large global data set from a spontaneous adverse event reporting system to assess the effect of age on reporting frequency of drug-associated liver injury with different clinical phenotypes. This study used only coded data provided in the released version of the WHO Safety 
Report VigiBase ${ }^{\mathrm{TM}}$ database without accessing identifiable private information and was reviewed by the University of North Carolina Office of Human Research Ethics, which determined that this study does not constitute human subjects research as defined under federal regulations [45 CFR 46.102 (d or f) and 21 CFR 56.102(c)(e)(I)] and does not require IRB approval.

Data Source: The WHO global individual case safety report (ICSR) VigiBase ${ }^{\mathrm{TM}}$ database is broadly utilized in pharmacovigilance and drug-induced liver injury research (Suzuki 2010). VigiBase ${ }^{\text {TM }}$ (1968-2013) is the world's largest spontaneous adverse event reporting system, with more than 6 million case reports from 104 countries; it includes both regulatory and voluntary sources (Lindquist 2008). The VigiBase ${ }^{\mathrm{TM}}$ data set released in the third quarter of 2012 was used.

Reporting frequency of liver events: Disproportionality of reporting frequency ratios for a drug-liver event pair in VigiBase ${ }^{\mathrm{TM}}$ were determined, relative to all other drugs and events in the database (relative reporting ratio). Applying Bayesian statistics, the relative reporting frequency of liver events was converted to the Empirical Bayes Geometric Mean (EBGM) of the relative reporting ratio with a $90 \%$ confidence interval (CI) (EB05 and EB95) using Empirica ${ }^{\mathrm{TM}}$ Signal (Oracle Corporation, Redwood Shores, CA) for 3 different age groups: children (0-17 years), adults (18-64 years), and the elderly (65 years or older). Liver-related cases were excluded if no age information was available. EBGM and $90 \% \mathrm{Cl}$ were computed using 4 custom liver events terms to address reporting frequency of liver events with different phenotypes. 
The 4 custom liver event terms were created, combining groups of 'Preferred Terms' (codes from the Medical Dictionary for Regulatory Activity, MedDRA): hepatocellular injury, cholestatic injury, acute liver failure and a combined overall term (which includes the prior three groups). Lists of 'Preferred terms,' used to define these custom terms, are summarized in Supplementary Table 1. As shown in the Supplementary Table 1, the 'Preferred Terms' used to define hepatocellular injury, cholestatic injury, and acute liver failure were not mutually exclusive, had some overlap among the three groups, and percentages were calculated using the total numbers of the reported liver events as denominators.

Study drugs: Two hundred thirty six drugs were evaluated in this study. Of the 385 drugs previously reported to be associated with hepatotoxicity (Drug Safety, 2010), 236 drugs were: 1) reported in the VigiBase ${ }^{\mathrm{TM}}$ with liver event related codes and 2) associated with an increased reporting frequency of liver events (defined as an EBGM equal to or greater than 2), which formed the data set for our analysis.

Drugs selectively affecting age groups: For the 236 drugs evaluated in this study, we compared reporting frequency of liver events among different age groups as detailed in the statistical analysis section and explored drugs which were associated with an increased reporting frequency of liver events in specific age groups. The identified drugs were further analyzed by: daily dose; lipophilicity, as measured by octanol-water partition coefficient (logP) (Chen 2013); plasma half-life; transporter interactions (Dawson 2012, Thompson 2012, Morgan 2013); metabolism (DailyMed), metabolism dependent inhibition, production of reactive metabolites or glutathione adducts (Sakatis 2012); mitochondrial impairment (in vitro or in vivo) (Pessayre 2012, Thompson 2012); 
genetic polymorphisms associated with hepatotoxicity or altered metabolism (Daly 2012, Russman 2010); age-related differences in clearance; biliary excretion, hypersensitivity or other attributes or liabilities by age group. To assure data completeness, drug lipophilicity, daily dose, mitochondrial effects, transporter interactions, biliary excretion and hypersensitivity were searched in PubMed and/or Google Scholar. A Google search was completed for drugs missing lipophilicity information alone. Product labels (DailyMed) were the primary source of data, followed by the published literature, for: plasma half-life, metabolism, aging-related differences in drug clearance, HLA-associated toxicity, production of reactive metabolites, glutathione adducts, protein covalent binding and metabolism dependent inhibition.

Statistical analyses: The results were reported in a descriptive manner. Total numbers of reported liver events were calculated for the 236 drugs using the combined overall liver event term. To compare frequency of liver events with different clinical phenotypes among the different age groups, we used Chi-square tests. To compare reporting frequency of liver events among the age groups, 90\% Cl of EBGM (EB05, EB95) using the combined overall liver term were compared among the groups. For instance, to identify drugs associated with an increased reporting frequency of liver events among children, drugs in which the EB05 for children were higher than EB95s for others (e.g. adults and elderly adults) were selected. Drugs associated with an increased reporting frequency of liver events among the elderly were selected by EB05 for the elderly higher than EB95 for others (e.g. children and non-elderly adults). Fisher's exact test was used to compare targeted drug characteristics of the 29 drugs with higher reporting in the children (relative to all other age groups) to the 10 drugs with higher reporting in the 
elderly (relative to all other age groups). Specifically, the proportion of drugs associated with high daily drug dose, lipophilicity, mitochondrial dysfunction, biliary excretion and bile salt export pump (BSEP) inhibition were compared between the two drug groups using Fisher's exact tests. Other drug characteristics, which were associated with significant missing information, were not statistically analyzed.

Statistical analyses were performed using JMP statistical software version 9.0 (SAS Institute Inc., Cary, NC) and STATA version 12.1 (StataCorp LP, College Station, Texas), and differences were considered statistically significant when the $p$-value(s) were less than 0.05 . P-values have not been adjusted for multiple comparisons due to exploratory nature of the analyses.

\section{Results}

A total of $1,813,187$ reported cases were related to the 236 drugs; 150,782 cases $(9 \%)$ were liver-related. Sixteen percent of these liver-related cases were missing age information and were excluded from the analysis, leaving 126,875 cases for evaluation.

Children were associated with a higher reporting frequency of acute liver failure (12\%) compared to adults $(8 \%)$ and the elderly $(6 \%)(P<0.00001$, Chi-square test) while the elderly were associated with a higher reporting frequency of cholestatic injury events (33\%) compared to adults $(27 \%)$ and children $(22 \%)(P<0.00001$, Chi-square test $)$ 
(Table 1). Most $(62 \%, n=78514)$ liver event reports were in adults age $18-64$, while $32 \%$ $(n=40560)$ were 65 years or older and only $6 \%(N=7801)$ were age $0-17$ (Table 1$)$.

When comparing the reporting frequency of liver events among the age groups, 10 drugs were associated with a significantly higher reporting frequency of liver events among the elderly, including: antibiotics (amoxicillin/clavulanate, flucloxacillin, fusidic acid, roxithromycin, and combination therapy with isoniazid, pyrazinamide and rifampin), steroids (cyproterone and danazol), and others (chlorpromazine, carbimazole, and nimesulide) (Table 2).

On the other hand, relative to adults and the elderly, 29 drugs were associated with a significantly higher reporting frequency of liver events in children including: antiretrovirals (abacavir, indinavir, ritonavir, and zidovudine), CNS agents (pemoline and valproic acid), antimetabolites (methotrexate and mercaptopurine), and antibiotics (oxacillin and minocycline) (Table 3).

\section{Characteristics of drugs associated with hepatotoxicity which differ among elderly and children}

Drug characteristics were examined for the identified 39 drugs to assess potential associations with differing reporting frequency by age group (Table 4). A high daily dose $(\geq 100 \mathrm{mg}$ ) was present in the large majority of the identified drugs $(87 \%)$, which was significantly higher than reported prevalence $(<32 \%)$ of this daily dose among the 230 drugs most commonly used in the US ( $p<0.0001)$ (Lammert 2008).

Regarding physicochemical drug properties, drugs associated with a higher pediatric reporting frequency had a tendency to be associated with mitochondrial 
dysfunction compared to drugs associated with a higher reporting frequency in the elderly ( $58.6 \%$ vs. $20 \%, p=0.06)$. On the other hand, drugs associated with a higher reporting frequency in the elderly tended to exhibit higher lipophilicity (as defined by $\log \mathrm{P}$ equal or greater than 3), when compared to drugs associated with a higher pediatric reporting frequency ( $50 \%$ vs. $21 \%)$. Although not statistically significant, biliary excretion and bile salt export pump (BSEP) inhibition were more commonly reported with drugs associated with a higher reporting frequency in the elderly than the children ( $70 \%$ vs. $44.8 \%, 30 \%$ vs. $13.8 \%$, respectively). Reactive metabolites, and glutathione (GSH) adducts were more commonly observed with drugs associated with a higher reporting frequency in the elderly, while covalent binding was more frequent with drugs associated with a higher pediatric reporting frequency, although these data were missing for many drugs. No apparent differences were noted between the two drug groups in reported hypersensitivity, metabolism dependent inhibition (MDI), or impact on multidrug resistance associated proteins $-2,-3$, and -4 (MRP-2, 3, 4). Across age groups, most drugs underwent hepatic metabolism; however, metabolism was incompletely defined for $41 \%$ (16/39) of drugs. Increased drug exposure or decreased clearance with aging were reported in 4 of 10 drugs with higher reporting in the elderly, in comparison to 1 of 29 drugs with higher reporting in children, although age-related differences in clearance were not assessed for some of these 29 drugs.

\section{Discussion}

In the global VigiBase ${ }^{\mathrm{TM}}$ dataset, phenotype-specific differences in reporting frequency of liver events were evident among different age groups: with more acute liver failure reporting among children and more cholestatic injury (with less 
hepatocellular injury) reporting among the elderly. Drug specific differences in the reporting frequency were also apparent among the age groups. Children exhibited a higher reporting frequency of liver events, relative to all other ages, associated with 29 drugs including CNS agents (e.g., valproic acid, pemoline), anti-retrovirals (3 protease inhibitors and 3 nucleoside reverse transcriptase inhibitors), antimetabolites (e.g., methotrexate) and antibiotics (e.g., minocycline). In contrast, the elderly exhibited an increased liver event reporting, relative to the other age groups, for 10 drugs, mainly antibiotics, including amoxicillin/ clavulanate and flucloxacillin.

Age-specific frequency, phenotypes, and outcomes of drug-induced liver injury are not yet fully characterized. Using the Spanish Drug-Induced Liver Injury registry, Lucena et al (2009) reported that older age is associated with cholestatic injury and younger age with hepatocellular damage. This observation is consistent with our findings of the reporting frequency data in the VigiBase. ${ }^{\mathrm{TM}}$ Furthermore, previous case-series studies using pediatric populations reported a predominance of hepatocellular injury. Although the true incidence of drug-induced liver injury cannot be addressed based on the reporting frequency of liver events in a spontaneous adverse event reporting system, these currently available data suggest that age may influence manifestations of druginduced liver injury.

In our study, the 39 drugs in which reporting frequency was associated with specific age groups ( 29 drugs among children and 10 drugs among the elderly), were further examined for their chemical, physical, and pharmacological characteristics and compared between the groups (the 29 vs. 10 drugs). Half of the drugs with higher reporting in the elderly combined both high daily dose and high lipophilicity, in 
comparison to a small minority of those in children. This potential susceptibility to highly lipophilic drugs in the elderly may be related to increasing body fat with aging, altering drug disposition, and/or different intracellular distribution. Biliary excretion and bile salt export pump (BSEP) inhibition were more common in drugs with higher reporting in the elderly versus children, which combined with the aging-related decrement in biliary function (Schmucker 2011, Morgan 2013), may contribute to the higher rate of cholestatic liver disease in the elderly. Few drugs associated with higher reporting in the elderly or children had HLA polymorphisms associated with hepatotoxicity (Table 4). Among the 29 drugs with higher liver event reporting in children, more than half are associated with mitochondrial dysfunction, in contrast to few in the elderly. Most compounds were associated with hypersensitivity. If confirmed, these drug-specific findings can be applied to the clinic and to drug development, to minimize the use of drugs resulting in mitochondrial impairment in children and drugs with high lipophilicity, biliary excretion, or BSEP inhibition in the elderly.

In a comparison of hepatotoxicity to first-line anti-tuberculosis drugs, adjusted for compliance, approximately 1 per 1000 children vs 31 per 1000 adults ( $\geq 55$ years) exhibited hepatotoxicity (Forget 2006). Generally, an increased risk of hepatotoxicity with antituberculosis therapy is associated with genetic polymorphisms ( $\mathrm{N}-$ acetyltransferase 2 slow acetylators, CYP2E1 c1/c1 wild type, glutathione S-transferase M1 null, and manganese superoxide dismutase mutant $C$ allele) (Huang 2012), older adults, and with malnutrition, alcohol abuse, viral hepatitis B or C, or HIV infection (Murray 2008). However, despite the relatively high frequency of liver injury with antituberculosis therapy, most patients develop adaptation due to initiation of 
antioxidant defenses and liver regeneration, and liver injury resolves (Pessayre 2012). However, liver regeneration declines with normal aging (Schmucker 2011), which may contribute to the aging-related increase in liver injury due to antituberculosis therapy. In this study, although we observed an increased reporting frequency of liver events related to first-line anti-tuberculosis drugs in the elderly, reporting frequency of individual anti-tuberculosis drugs were higher in children. Reasons for this discrepancy are uncertain.

The strengths of this study include its use of the global VigiBase ${ }^{\mathrm{TM}}$ with over 6 million drug safety reports over decades, which span all ages and marketed drugs. The large dataset provided sufficient cases to stratify data across age categories of interest. Drug properties were identified which were associated with age-specific liver event reporting. Potential mechanisms of age-specific susceptibilities were highlighted by comparing these results to nonclinical, physiologic, and epidemiologic studies, including druginduced liver injury registries.

This study is limited by it's use of the WHO VigiBase; ${ }^{\text {TM }}$ this database includes largely voluntarily reported adverse events from health care providers, patients, and regulators. While some countries mandate adverse drug reporting, US reporting is voluntary and yields most of the adverse drug reports in VigiBase. ${ }^{\mathrm{TM}}$ The two major issues of this database include: 1) under-reporting of events and 2) incompleteness or inaccuracy of reported data. Providers are not reimbursed or rewarded for reporting adverse drug events, so less than $10 \%$ of events are reported; many events are reported with incomplete, or inaccurately recalled, information. Furthermore, a reporting bias can arise with publicity about a suspect drug adverse drug reaction resulting in 
transiently increased reporting. For example, while propylthiouracil has been marketed for 60 years, liver injury event reports in children increased 10-fold between 1983-2003, with severe liver injury and death most frequent in children (Rivkees 2010). This finding resulted in "Dear Practitioner" letters warning of this suspect adverse drug reaction, announcements to Endocrine societies, and publications, and further increased reporting through 2008 (Rivkees 2010). To estimate the proportion of reporting related to publicity, one can determine if reporting has declined in followup years. Symptomatic drug-induced liver injury is rare and frequently misdiagnosed. Yet, drug: liver event reporting can increase due to co-existing disease without a true causal association. For example, congestive heart failure in the elderly may contribute to over-reporting of cholestatic liver disease. Additionally, unreliable high signal scores can result from small numbers of events, which typically decrease as additional data accrues. Therefore, a high disproportionality score does not necessarily indicate either a causal association of the drug and the liver event, or even a high incidence of liver injury. High signal scores can arise from background disease in the population using the suspect drug, publicity about suspect drug adverse drug reactions resulting in a reporting bias, concomitant medicines frequently paired with the suspect drug, or differences in drug dosing or frequency. Hence, this WHO data generates hypotheses regarding potential causal associations between drugs and events, to be further examined in prospective druginduced liver injury registries, epidemiology studies and clinical research. Another limitation of the WHO VigiBase ${ }^{\mathrm{TM}}$ is that exact drug dosage, the frequency and duration of drug usage, and chronological relationship of drugs with events are unknown, so the liver injury incidence cannot be assessed. Nevertheless, these analyses raise refined 
research questions about age-related toxicity differences, which can be further evaluated to optimize drug safety and monitoring in children and the elderly.

In summary, our data-mining analysis addressed age-related differences in reporting of drug-associated liver injury and provided refined theories for future investigations related to age-specific susceptibilities. Likely due to inborn mitochondrial defects, higher reporting was observed in children with drugs associated with mitochondrial impairment: CNS agents, anti-retrovirals, antimetabolites and antibiotics. With age-related declines in biliary function and liver regeneration, higher reporting in the elderly appeared in highly lipophilic drugs with biliary excretion. An enhanced understanding of age-related differences in hepatotoxicity will help to identify and address mechanisms of injury, and improve patient safety. With confirmation, these findings can inform clinicians and drug development to minimize use of drugs resulting in mitochondrial impairment in children and highly lipophilic drugs in the elderly. 


\section{References}

1. Alfirevic, Ana, and Munir Pirmohamed. "Drug induced hypersensitivity and the HLA complex." Pharmaceuticals 4, no. 1 (2010): 69-90.

2. Almenoff, June, Joseph M. Tonning, A. Lawrence Gould, Ana Szarfman, Manfred Hauben, Rita Ouellet-Hellstrom, Robert Ball et al. "Perspectives on the use of data mining in pharmacovigilance." Drug safety 28, no. 11 (2005): 981-1007.

3. Almenoff, June S., Karol K. LaCroix, Nancy A. Yuen, David Fram, and William DuMouchel. "Comparative performance of two quantitative safety signalling methods." Drug safety 29, no. 10 (2006): 875-887.

4. Apostolova, Nadezda, Ana Blas-García, and Juan V. Esplugues. "Mitochondrial interference by anti-HIV drugs: mechanisms beyond Pol-y inhibition." Trends in Pharmacological Sciences 32, no. 12 (2011): 715-725.

5. Argikar, Upendra A., and Rory P. Remmel. "Effect of aging on glucuronidation of valproic acid in human liver microsomes and the role of UDP-glucuronosyltransferase UGT1A4, UGT1A8, and UGT1A10." Drug Metabolism and Disposition 37.1 (2009): 229236. 
6. Bernareggi, Alberto. "Clinical pharmacokinetics of nimesulide." Clinical pharmacokinetics 35, no. 4 (1998): 247-274.

7. Bode KA, Donner MG, Leier I, Keppler D: Inhibition of transport across the hepatocyte canalicular membrane by the antibiotic fusidate. Biochem Pharmacol 2002; 64: 151-158.

8. Boelsterli, Urs A. "Mechanisms of NSAID-induced hepatotoxicity." Drug Safety 25, no. 9 (2002): 633-648.

9. Bohan, T. P., et al. "Effect of L-carnitine treatment for valproate-induced hepatotoxicity." Neurology 56.10 (2001): 1405-1409.

10. Chem Exper Chemical Directory at: https://www.chemexper.com (Accessed 8Aug13).

11. Chen, Li-Hsin, et al. "microRNA and aging: a novel modulator in regulating the aging network." Ageing Research Reviews 9 (2010): S59-S66. 
12. Chen, Minjun, Jürgen Borlak, and Weida Tong. "High lipophilicity and high daily dose of oral medications are associated with significant risk for drug-induced liver injury." Hepatology 58, no. 1 (2013): 388-396.

13. Cheung, Corjena K., Jean F. Wyman, and Linda L. Halcon. "Use of complementary and alternative therapies in community-dwelling older adults." The Journal of Alternative and Complementary Medicine 13, no. 9 (2007): 997-1006.

14. Chew, G. Y. J., C. A. Hawkins, M. Cherian, and M. Hurwitz. "Roxithromycin induced hypersensitivity pneumonitis." Pathology 38, no. 5 (2006): 475-477.

15. Chowdhury, Abhijit, Amal Santra, Koutilya Bhattacharjee, Subhadip Ghatak, Dhira Rani Saha, and Gopal Krishna Dhali. "Mitochondrial oxidative stress and permeability transition in isoniazid and rifampicin induced liver injury in mice." Journal of Hepatology 45, no. 1 (2006): 117-126.

16. DailyMed at: http://dailymed.nIm.nih.gov (Accessed 18Aug13).

17. Daly, Ann K., and Christopher P. Day. "Genetic association studies in drug-induced liver injury." Drug Metabolism Reviews 44, no. 1 (2012): 116-126. 
18. Dawson, Sarah, Simone Stahl, Nikki Paul, Jane Barber, and J. Gerald Kenna. "In vitro inhibition of the bile salt export pump correlates with risk of cholestatic druginduced liver injury in humans." Drug Metabolism and Disposition 40, no. 1 (2012): 130138.

19. de Abajo FJ, Montero D, Madurga M, et al. Acute and clinically relevant druginduced liver injury: a population based case-control study. Br J Clin Pharmacol 2004; 58:71-80.

20. Dealberto, Marie-Jose CC. "Valproate-induced hyperammonaemic encephalopathy: review of 14 cases in the psychiatric setting." International clinical psychopharmacology 22.6 (2007): 330.

21. Devarbhavi, Harshad, et al. "Drug-Induced liver injury with hypersensitivity features has a better outcome: A single-center experience of 39 children and adolescents." Hepatology 54.4 (2011): 1344-1350.

22. Dykens, James A., Lisa D. Marroquin, and Yvonne Will. "Strategies to reduce latestage drug attrition due to mitochondrial toxicity." (2007): 161-175. 
23. Evered, D. C. "Endocrine and metabolic diseases. Treatment of thyroid disease: I." British medical journal 1, no. 6004 (1976): 264-266.

24. Ferrajolo, Carmen, et al. "Drug-induced hepatic injury in children: a case/non-case study of suspected adverse drug reactions in VigiBase." British journal of clinical pharmacology 70.5 (2010): 721-728.

25. Food and Drug Administration Import Refusal Report: Josamycin. http://www.accessdata.fda.gov/scripts/importrefusals/ir_detail.cfm?Entryld=DO70110115-9\&Docld=1\&Lineld=1\&Sfxld= (Accessed 24Sept13).

26. Forget, Eric J., and Dick Menzies. "Adverse reactions to first-line antituberculosis drugs." Expert Opin. Drug Saf. (2006) 5(2):231-249.

27. Freymond, N., A. Catelain, F. Cousin, and J. F. Nicolas. "Skin delayed-type hypersensitivity to josamycin." Allergy 58, no. 12 (2003): 1319-1320.

28. Garcia Rodriguez LA, Stricker BH, Zimmerman HJ. Risk of acute liver injury 
associated with the combination of amoxicillin and clavulanic acid. Arch

Intern Med. 1996;156:1327-1332.

29. Grolleau-Julius, Annabelle, Donna Ray, and Raymond L. Yung. "The role of epigenetics in aging and autoimmunity." Clinical Reviews in Allergy and Immunology 39.1 (2010): 42-50.

30. Gurwitz JH, Field TS, Harrold LR, et al. Incidence and Preventability of Adverse Drug Events Among Older Persons in the Ambulatory Setting. JAMA. 2003;289(9):1107-1116. doi:10.1001/jama.289.9.1107.

31. Han, Derick, Lily Dara, Sanda Win, Tin Aung Than, Liyun Yuan, Sadeea Q. Abbasi, Zhang-Xu Liu, and Neil Kaplowitz. "Regulation of drug-induced liver injury by signal transduction pathways: critical role of mitochondria." Trends in pharmacological sciences (2013).

32. Hohensinner, Philipp J., Jörg J. Goronzy, and Cornelia M. Weyand. "Telomere dysfunction, autoimmunity and aging." Aging and disease 2.6 (2011): 524. 
33. Horio, Takeshi. "Chlorpromazine photoallergy: coexistence of immediate and delayed type." Archives of Dermatology 111, no. 11 (1975): 1469.

34. Huang YS. Recent global endeavors in the detection and prevention of druginduced liver injury. Journal of the Formosan Medical Association 2012;111:237-238.

35. Hunt CM, Strater S. Effect of Normal Aging on the Activity of Human Hepatic Cytochrome P-4502E1. Biochem Pharmacol 1990; 40(7): 1666-1669.

36. Hunt, Christine M., William R. Westerkam, Gregg M. Stave, and Joanne AP Wilson. "Hepatic cytochrome P-4503A (CYP3A) activity in the elderly." Mechanisms of ageing and development 64, no. 1 (1992): 189-199.

37. Hunt, Christine M., William R. Westerkam, and Gregg M. Stave. "Effect of age and gender on the activity of human hepatic CYP3A." Biochemical pharmacology 44, no. 2 (1992): 275-283.

38. Hussaini SH, O'Brien CS, Despott EJ, et al. Antibiotic therapy: a major cause of drug-induced jaundice in southwest England. Eur J Gastroenterol Hepatol.2007;19:1520.). 
39. Jemnitz, Katalin, Zsuzsa Veres, Regina Tugyi, and Laszlo Vereczkey. "Biliary efflux transporters involved in the clearance of rosuvastatin in sandwich culture of primary rat hepatocytes." Toxicology in Vitro 24, no. 2 (2010): 605-610.

40. Kalliokoski, A., Niemi M. "Impact of OATP transporters on pharmacokinetics." British Journal of Pharmacology 158, no. 3 (2009): 693-705.

41. Karras, Spiros, Eleni Memi, Evangelia Kintiraki, and Gerasimos E. Krassas. "Pathogenesis of propylthiouracil-related hepatotoxicity in children: present concepts." (2012): 623-630.

42. Kearns GL, Abdel-Rahman SN, Alander SW, et al. "Developmental pharmacologydrug disposition, action, and therapy in infants and children." New England Journal of Medicine 349.12 (2003): 1157-1167.

43. Klotz, Ulrich. Pharmacokinetics and drug metabolism in the elderly. Drug metabolism reviews 41.2 (2009): 67-76. 
44. Kuhnz, W., H. Kulmann, and A. Fuhrmeister. "Investigation into the age-dependence of the pharmacokinetics of cyproterone acetate in healthy male volunteers." European journal of clinical pharmacology 53, no. 1 (1997): 75-80.

45. Lammert, Craig, Stefan Einarsson, Chandan Saha, Anna Niklasson, Einar Bjornsson, and Naga Chalasani. "Relationship between daily dose of oral medications and idiosyncratic drug-induced liver injury: Search for signals." Hepatology 47, no. 6 (2008): 2003-2009.

46. Lammert, Craig, et al. "Oral medications with significant hepatic metabolism at higher risk for hepatic adverse events." Hepatology 51.2 (2010): 615-620.

47. Larson, Anne M., et al. "Acetaminophen-induced acute liver failure: Results of a United States multicenter, prospective study." Hepatology 42.6 (2005): 1364-1372.

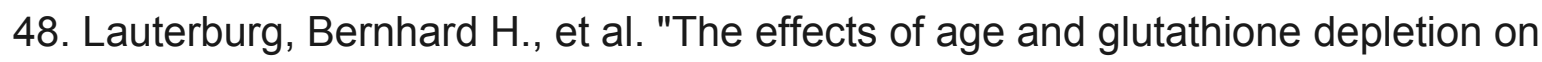
hepatic glutathione turnover in vivo determined by acetaminophen probe analysis." Journal of Pharmacology and Experimental Therapeutics 213.1 (1980): 54-58.

49. Lindquist, Marie. "VigiBase, the WHO global ICSR database system: basic facts." 
Drug Information Journal 42, no. 5 (2008): 409-419.

50. Lo'pez-Lluch, G., Irusta, P.M., Navas, P. and de Cabo,R. (2008) Mitochondrial biogenesis and healthy aging. Exp Gerontol 43: 813_819.

51. Lucena, M. Isabel, Raúl J. Andrade, Neil Kaplowitz, Miren García-Cortes, M. Carmen Fernández, Manuel Romero-Gomez, Miguel Bruguera et al. "Phenotypic characterization of idiosyncratic drug-induced liver injury: The influence of age and sex." Hepatology 49, no. 6 (2009): 2001-2009.

52. Lucena, M. Isabel, et al. "Susceptibility to amoxicillin-clavulanate-induced liver injury is influenced by multiple HLA class I and II alleles." Gastroenterology 141.1 (2011): 338347.

53. MHRA Drug Safety Update.

http://www.mhra.gov.uk/Safetyinformation/DrugSafetyUpdate/CON087674 (Accessed 24Sept13).

54. Marotta, Paul J., and Roberts, Eve A. "Pemoline hepatotoxicity in children." The Journal of pediatrics 132, no. 5 (1998): 894-897. 
55. McFarland, R., et al. "Reversible valproate hepatotoxicity due to mutations in mitochondrial DNA polymerase Y (POLG1)." Archives of disease in childhood 93.2 (2008): 151-153.

56. Mindikoglu, Ayse L., Laurence S. Magder, and Arie Regev. "Outcome of liver transplantation for drug-induced acute liver failure in the United States: Analysis of the united network for organ sharing database." Liver Transplantation 15, no. 7 (2009): 719729.

57. Minuesa, Gerard, Isabel Huber-Ruano, Marçal Pastor-Anglada, Hermann Koepsell, Bonaventura Clotet, and Javier Martinez-Picado. "Drug uptake transporters in antiretroviral therapy." Pharmacology \& therapeutics 132, no. 3 (2011): 268-279.

58. Molleston, Jean P., et al. "Characteristics of idiosyncratic drug-induced liver injury in children: results from the DILIN prospective study." Journal of pediatric gastroenterology and nutrition 53.2 (2011): 182-189.

59. Moore, Thomas J., Michael R. Cohen, and Curt D. Furberg. "Serious adverse drug events reported to the Food and Drug Administration, 1998-2005." Archives of Internal 
Medicine 167.16 (2007): 1752-1759.

60. Morgan, Ryan E., Carlo J. van Staden, Yuan Chen, Natarajan Kalyanaraman, Jackson Kalanzi, Robert T. Dunn, Cynthia A. Afshari, and Hisham K. Hamadeh. "A Multifactorial Approach to Hepatobiliary Transporter Assessment Enables Improved Therapeutic Compound Development." Toxicological Sciences (2013).

61. Murray, Karen F., et al. "Drug-related hepatotoxicity and acute liver failure." Journal of pediatric gastroenterology and nutrition 47.4 (2008): 395-405.

62. Nadanaciva, Sashi, Keith Dillman, David F. Gebhard, Alka Shrikhande, and Yvonne Will. "High-content screening for compounds that affect mtDNA-encoded protein levels in eukaryotic cells." Journal of biomolecular screening 15, no. 8 (2010): 937-948.

63. National Institutes of Health. LiverTox at: http://livertox.nIm.nih.gov/Oxacillin.htm (Accessed 18Sept13).

64. Norrby, S. R. "Antibiotic therapy in aging patients." Bulletin of the New York Academy of Medicine 63, no. 6 (1987): 519. 
65. Ostapowicz, George, Robert J. Fontana, Frank V. Schiødt, Anne Larson, Timothy J. Davern, Steven HB Han, Timothy M. McCashland et al. "Results of a prospective study of acute liver failure at 17 tertiary care centers in the United States." Annals of Internal Medicine 137, no. 12 (2002): 947-954.

66. Ouslander, Joseph G. "Drug therapy in the elderly." Annals of Internal Medicine 95, no. 6 (1981): 711-722.

67. Papapetrou, P. D., B. Marchant, H. Gavras, and W. D. Alexander. "Biliary excretion of 35 S-labelled propylthiouracil, methimazole and carbimazole in untreated and pentobarbitone pretreated rats." Biochemical pharmacology 21, no. 3 (1972): 363-370.

68. Pauli-Magnus, Christiane, and Peter J. Meier. "Hepatobiliary transporters and druginduced cholestasis." Hepatology 44, no. 4 (2006): 778-787.

69. Pessayre, Dominique, Bernard Fromenty, Alain Berson, et al. Central role of mitochondria in drug-induced liver injury. Drug Metab Review 2012; 44(1): 34-87. 
70. Phiel, Christopher J., et al. "Histone deacetylase is a direct target of valproic acid, a potent anticonvulsant, mood stabilizer, and teratogen." Journal of Biological Chemistry 276.39 (2001): 36734-36741.

71. Puri, Surendra K., and Howard B. Lassman. "Roxithromycin: a pharmacokinetic review of a macrolide." Journal of Antimicrobial Chemotherapy 20, no. suppl B (1987): 89-100.

72. Ramappa, Vidyasagar, and Guruprasad P. Aithal. "Hepatotoxicity related to antitubercular drugs: Mechanisms and management." Journal of Clinical and Experimental Hepatology (2012).

73. Reuben, Adrian, David G. Koch, and William M. Lee. "Drug-induced acute liver failure: Results of a US multicenter, prospective study." Hepatology 52, no. 6 (2010): 2065-2076.

74. Riess, ChristophE, and Leena Bruckner-Tuderman. "Delayed type hypersensitivity to fusidic acid in patients with chronic dermatitis." The Lancet 335, no. 8704 (1990): $1525-1526$. 
75. Rivkees, Scott A., and Ana Szarfman. "Dissimilar hepatotoxicity profiles of propylthiouracil and methimazole in children." Journal of Clinical Endocrinology \& Metabolism 95, no. 7 (2010): 3260-3267.

76. Rosh, Joel R., Dellert, Susan F., Narkewicz, Michael et al. Four Cases of Severe Hepatotoxicity Associated With Pemoline: Possible Autoimmune Pathogenesis . Pediatrics 1998;101;921-923 DOI: 10.1542/peds.101.5.921.

77. Russmann, Stefan, Alexander Jetter, and Gerd A. Kullak-Ublick. "Pharmacogenetics of drug-induced liver injury." Hepatology 52, no. 2 (2010): 748-761.

78. Saab, Lea, Jean Peluso, Christian D. Muller, and Genevieve Ubeaud-Sequier. "Implication of hepatic transporters (MDR1 and MRP2) in inflammation-associated idiosyncratic drug-induced hepatotoxicity investigated by microvolume cytometry." Cytometry Part A (2013).

79. Sakatis MZ, Reese MJ, et al. Preclinical Strategy to Reduce Clinical Hepatotoxicity Using in Vitro Bioactivation Data for $>200$ Compounds. Chem. Res. Toxicol. 2012, 25, 2067-2082. 
80. Schiødt, Frank V., Raymond T. Chung, Michael L. Schilsky, J. Eileen Hay, Erik Christensen, and William M. Lee. "Outcome of acute liver failure in the elderly." Liver Transplantation 15, no. 11 (2009): 1481-1487.

81. Schmucker, Douglas L., and Henry Sanchez. "Liver regeneration and aging: a current perspective." Current gerontology and geriatrics research 2011 (2011).

82. Schwartz, Janice B. Erythromycin breath test results in elderly, very elderly, and frail elderly persons. Clinical Pharmacology \& Therapeutics 79.5 (2006): 440-448.

83. Sgro C, Clinard F, Ouazir K, et al. Incidence of drug-induced hepatic injuries: a French population-based study. Hepatology 2002; 36:451-5.

84. Squires Jr, Robert H. "Acute liver failure in children." Clin Liver Dis 10 (2006): 149168.

85. Stewart, Joanna D., et al. "Polymerase y Gene POLG determines the risk of sodium valproate-induced liver toxicity." Hepatology 52.5 (2010): 1791-1796. 
86. Suzuki, Ayako, Raul J. Andrade, Einar Bjornsson, M. Isabel Lucena, William M. Lee, Nancy A. Yuen, Christine M. Hunt, and James W. Freston. "Drugs Associated with Hepatotoxicity and their Reporting Frequency of Liver Adverse Events in VigiBase ${ }^{\mathrm{TM}}$." Drug safety 33, no. 6 (2010): 503-522.

87. Tachibana, A., H. Sasaki, T. Watanabe, K. Yano, and T. Sado. "Absorption, distribution and excretion of 14C-josamycin and 14C-josamycin propionate in rats (author's transl)]." The Japanese Journal of Antibiotics 28, no. 4 (1975): 558.

88. Tapner NJ, Jones BE, Wu WM, Farrell GC. Toxicity of low dose aza- thioprine and 6-mercaptopurine in rat hepatocytes. Roles of xanthine oxidase and mitochondrial injury. J Hepatol 2004;40:454-463.

89. Thompson, Richard A., Emre M. Isin, Yan Li, et al. In Vitro Approach to Assess the Potential for Risk of Idiosyncratic Adverse Reactions Caused by Candidate Drugs. Chem. Res. Toxicol. 2012, 25, 1616-1632.

90. Turnheim, Klaus. "Pharmacokinetic dosage guidelines for elderly subjects." (2005): 33-48. 
91. U.S. Census Bureau, at:

http://www.census.gov/newsroom/releases/archives/2010_census/cb12-239.html

(Accessed 7Aug13).

92. Van Steenbergen, Werner, Pascal Peeters, Joris De Bondt, Dirk Staessen, Henri Büscher, Thiery Laporta, Tania Roskams, and Valeer Desmet. "Nimesulide-induced acute hepatitis: evidence from six cases." Journal of Hepatology 29, no. 1 (1998): 135141.

93. Werner, Tamara, et al. "Effects of Valproate on Acylcarnitines in Children with Epilepsy Using ESI-MS/MS." Epilepsia 48.1 (2007): 72-76.

94. Wolf, Kristina K., Sapana Vora, Lindsey O. Webster, Grant T. Generaux, Joseph W. Polli, and Kim LR Brouwer. "Use of cassette dosing in sandwich-cultured rat and human hepatocytes to identify drugs that inhibit bile acid transport." Toxicology in Vitro 24, no. 1 (2010): 297-309.

95. Yang, Kyunghee, Kathleen Köck, Alexander Sedykh, Alexander Tropsha, and Kim LR Brouwer. "An updated review on drug-induced cholestasis: Mechanisms and investigation of physicochemical properties and pharmacokinetic parameters." Journal 
of pharmaceutical sciences (2013).

96. Zamek-Gliszczynski, Maciej J., Keith A. Hoffmaster, Xianbin Tian, Rong Zhao, Joseph W. Polli, Joan E. Humphreys, Lindsey O. Webster, Arlene S. Bridges, J. Cory Kalvass, and Kim LR Brouwer. "Multiple mechanisms are involved in the biliary excretion of acetaminophen sulfate in the rat: role of Mrp2 and Bcrp1." Drug Metabolism and Disposition 33, no. 8 (2005): 1158-1165. 
Table 1. Overall frequency of WHO liver event reporting by age group

\begin{tabular}{|l|l|l|l|}
\hline Liver Event Type & $\begin{array}{l}\text { Children } \\
\text { (Age 0-17) }\end{array}$ & $\begin{array}{l}\text { Adults } \\
\text { (Age 18-64) }\end{array}$ & $\begin{array}{l}\text { Elderly } \\
(\text { Age } \geq 65)\end{array}$ \\
\hline Cholestatic injury* $^{*}$ & $22 \%$ & $27 \%$ & $33 \%$ \\
\hline Hepatocellular injury* & $82 \%$ & $81 \%$ & $77 \%$ \\
\hline Acute liver failure* & $12 \%$ & $8 \%$ & $6 \%$ \\
\hline Total N of cases & 7801 & 78514 & 40560 \\
\hline
\end{tabular}

*not mutually exclusive

Total numbers of WHO reported liver events were calculated using the combined overall term for the 236 drugs.

The classification of different clinical phenotypes, hepatocellular injury, cholestatic injury, and acute liver failure, was not mutually exclusive and percentages were calculated using the total numbers of the reported liver events as denominators. 
Table 2. Drugs associated with significantly higher WHO liver event reporting frequency among the elderly

\begin{tabular}{|c|c|c|c|c|c|c|c|c|c|}
\hline \multirow{2}{*}{ Generic Name } & \multicolumn{3}{|c|}{$\mathrm{N}$ of drug-specific reports } & \multicolumn{3}{|c|}{$\mathrm{N}$ of drug-specific liver reports } & \multicolumn{3}{|c|}{ EBGM } \\
\hline & Children & Adults & Elderly & Children & Adults & Elderly & Children & Adults & Elderly \\
\hline $\begin{array}{l}\text { Amoxicillin and } \\
\text { Clavulanate }^{*}\end{array}$ & 7241 & 23559 & 12517 & 190 & 2608 & 2218 & 1.5 & 3.0 & 4.6 \\
\hline Carbimazole & 142 & 2789 & 1563 & 1 & 246 & 207 & 0.4 & 2.4 & 3.3 \\
\hline Chlorpromazine & 741 & 9871 & 2197 & 52 & 979 & 373 & 2.5 & 2.3 & 3.9 \\
\hline Cyproterone & 58 & 800 & 1271 & 4 & 81 & 347 & 1.9 & 2.6 & 5.7 \\
\hline Danazol & 43 & 2699 & 337 & 2 & 181 & 64 & 1.3 & 1.8 & 4.4 \\
\hline Flucloxacillin & 1087 & 4153 & 2845 & 67 & 957 & 972 & 2.9 & 5.4 & 7.9 \\
\hline Fusidic Acid & 476 & 1492 & 1294 & 38 & 217 & 378 & 3.8 & 3.5 & 7.0 \\
\hline $\begin{array}{l}\text { Isoniazid And } \\
\text { Pyrazinamide And } \\
\text { Rifampicin }\end{array}$ & 57 & 830 & 372 & 9 & 243 & 147 & 4.5 & 7.2 & 10.0 \\
\hline Nimesulide & 227 & 3542 & 1244 & 6 & 367 & 210 & 1.2 & 3.1 & 4.8 \\
\hline Roxithromycin & 875 & 4306 & 1646 & 28 & 306 & 170 & 1.5 & 1.9 & 2.5 \\
\hline
\end{tabular}

${ }^{*}$ pooled

Total numbers of WHO drug-specific reports and drug-specific liver reports for drugs among the 236 drugs associated with hepatotoxicity which showed a significantly higher reporting frequency in the elderly (age 65 or greater). A higher EBGM score indicates a greater strength of association of the liver event with the drug. 
Table 3. Drugs associated with significantly higher WHO liver event reporting frequency among children

\begin{tabular}{|c|c|c|c|c|c|c|c|c|c|}
\hline \multirow{2}{*}{ Generic Name } & \multicolumn{3}{|c|}{$\mathrm{N}$ of drug-specific reports } & \multicolumn{3}{|c|}{$\mathrm{N}$ of drug-specific liver reports } & \multicolumn{3}{|c|}{ EBGM } \\
\hline & Children & Adults & Elderly & Children & Adults & Elderly & Children & Adults & Elderly \\
\hline Abacavir & 237 & 4899 & 158 & 32 & 443 & 14 & 6.6 & 2.1 & 2.0 \\
\hline Allopurinol & 568 & 20542 & 29098 & 58 & 1462 & 1632 & 4.2 & 1.7 & 1.5 \\
\hline Amiodarone & 269 & 8706 & 23412 & 28 & 670 & 1687 & 4.6 & 1.8 & 1.9 \\
\hline Atorvastatin & 466 & 41827 & 42089 & 30 & 2581 & 2414 & 3.8 & 1.7 & 1.8 \\
\hline Bosentan & 281 & 3123 & 2391 & 66 & 856 & 644 & 12.4 & 8.6 & 9.0 \\
\hline Carbamazepine & 7615 & 35448 & 9859 & 591 & 2658 & 847 & 3.1 & 1.9 & 2.1 \\
\hline $\begin{array}{l}\text { Codeine And } \\
\text { Paracetamol }\end{array}$ & 745 & 16607 & 9348 & 37 & 772 & 403 & 1.9 & 1.2 & 1.1 \\
\hline Dapsone & 236 & 3216 & 504 & 34 & 397 & 64 & 5.3 & 3.0 & 3.1 \\
\hline Didanosine & 541 & 7678 & 172 & 60 & 1016 & 22 & 6.1 & 3.0 & 2.7 \\
\hline Ethambutol & 650 & 9698 & 3108 & 164 & 1930 & 756 & 12.1 & 5.1 & 6.3 \\
\hline Fluconazole & 1324 & 15134 & 4583 & 157 & 1543 & 467 & 6.2 & 2.7 & 2.8 \\
\hline $\begin{array}{l}\text { Hydrocodone \& } \\
\text { Paracetamol }\end{array}$ & 351 & 20816 & 6541 & 24 & 915 & 225 & 2.7 & 1.4 & 1.1 \\
\hline Indinavir & 208 & 7100 & 158 & 27 & 646 & 9 & 5.1 & 1.9 & 1.2 \\
\hline
\end{tabular}




\begin{tabular}{|c|c|c|c|c|c|c|c|c|c|}
\hline \multirow{2}{*}{ Generic Name } & \multicolumn{3}{|c|}{$\mathrm{N}$ of drug-specific reports } & \multicolumn{3}{|c|}{$\mathrm{N}$ of drug-specific liver reports } & \multicolumn{3}{|c|}{ EBGM } \\
\hline & Children & Adults & Elderly & Children & Adults & Elderly & Children & Adults & Elderly \\
\hline Isoniazid & 1282 & 14247 & 4070 & 319 & 3047 & 1109 & 9.7 & 5.3 & 6.7 \\
\hline Josamycin & 359 & 445 & 151 & 32 & 41 & 16 & 4.2 & 2.2 & 1.9 \\
\hline Mercaptopurine & 1291 & 1982 & 296 & 150 & 230 & 38 & 5.4 & 3.3 & 3.3 \\
\hline Methotrexate & 5077 & 34548 & 16732 & 509 & 1843 & 552 & 4.8 & 1.6 & 1.0 \\
\hline Minocycline & 1881 & 6855 & 892 & 213 & 597 & 68 & 3.4 & 2.3 & 1.9 \\
\hline Nelfinavir & 460 & 3732 & 99 & 39 & 356 & 2 & 5.4 & 2.3 & 0.7 \\
\hline Oxacillin & 630 & 1167 & 503 & 65 & 96 & 45 & 5.0 & 1.9 & 2.0 \\
\hline Paracetamol & 30153 & 89224 & 45379 & 1139 & 6521 & 2718 & 2.3 & 2.0 & 1.7 \\
\hline Pemoline & 724 & 703 & 67 & 216 & 90 & 3 & 9.2 & 3.0 & 1.0 \\
\hline Propylthiouracil & 177 & 2246 & 588 & 35 & 242 & 42 & 7.4 & 3.1 & 1.7 \\
\hline Pyrazinamide & 571 & 8167 & 2134 & 159 & 2004 & 713 & 13.6 & 6.5 & 8.6 \\
\hline Rifampicin & 1324 & 13488 & 5240 & 326 & 2978 & 1451 & 12.1 & 5.6 & 7.1 \\
\hline Ritonavir & 465 & 8357 & 247 & 87 & 1012 & 24 & 10.0 & 2.9 & 2.4 \\
\hline Sulfasalazine & 533 & 10449 & 3621 & 54 & 1014 & 245 & 3.4 & 2.5 & 1.7 \\
\hline Valproic Acid & 11667 & 39623 & 6638 & 1084 & 2444 & 451 & 4.1 & 1.6 & 1.8 \\
\hline Zidovudine & 1817 & 12872 & 234 & 160 & 917 & 12 & 6.4 & 1.8 & 1.2 \\
\hline
\end{tabular}

Total numbers of WHO drug-specific reports and drug-specific liver reports for drugs among the 236 drugs associated 
with hepatotoxicity which showed a significantly higher reporting frequency in children (age 0 to 17). A higher EBGM score indicates a greater strength of association of the liver event with the drug. 
Table 4. Characteristics of drugs with higher WHO liver event reporting frequency in children or the elderly

\begin{tabular}{|c|c|c|c|c|c|c|c|c|c|c|c|c|c|}
\hline Drug & $\begin{array}{l}\text { Daily } \\
\text { dose }\end{array}$ & $\log P$ & $\begin{array}{l}\text { Plasma } \\
\mathrm{t} 1 / 2(\mathrm{hrs})\end{array}$ & BSEP & MRP & $\begin{array}{l}\text { Biliary } \\
\text { excr }\end{array}$ & $\begin{array}{l}\text { Mito } \\
\text { dysftn }\end{array}$ & $\mathrm{HLA}$ & $\begin{array}{l}\text { Hyper- } \\
\text { sens }\end{array}$ & $\begin{array}{l}\text { React } \\
\text { metab }\end{array}$ & $\begin{array}{l}\text { GSH } \\
\text { adduct }\end{array}$ & $\begin{array}{l}\text { Coval } \\
\text { bindg }\end{array}$ & MDI \\
\hline \multicolumn{14}{|l|}{$\begin{array}{l}\text { High child report } \\
\text { frequency }\end{array}$} \\
\hline Abacavir ${ }^{12,16,69}$ & 600 & 0.8 & 1.5 & 0 & 0 & 0 & 1 & 1 & 1 & 1 & 0 & 0 & 0 \\
\hline Allopurinol12,16,79,95 & 400 & -1.5 & 1 & 0 & 0 & 1 & 0 & 0 & 1 & 0 & 0 & 0 & 0 \\
\hline Amiodarone $^{12,16,60,68,69,79}$ & 200 & 7.2 & $36-58$ & 0 & 0 & 1 & 1 & 0 & 1 & 0 & 0 & 0 & 1 \\
\hline Atorvastatin $16,22,60,79$ & $10-80$ & 4.53 & 14 & 1 & 1 & 1 & 1 & 0 & 0 & 0 & 0 & 1 & 0 \\
\hline Bosentan 12,16,18 & 250 & 3.9 & 5 & 1 & 0 & 1 & 0 & 0 & 1 & 0 & 0 & 0 & 0 \\
\hline Carbamazepine ${ }^{12,16,69,79,89}$ & 1000 & 2.7 & $12-65$ & 0 & 0 & 1 & 0 & 1 & 1 & 1 & 1 & 1 & 0 \\
\hline $\begin{array}{l}\text { Codeine \& paracet- } \\
\text { amol }^{12,16,69,79,89}\end{array}$ & 3000 & 0.7 & $1.2-3$ & 0 & 1 & 0 & 1 & 0 & 0 & 0 & 1 & 1 & 0 \\
\hline Dapsone $e^{12,16,18,69}$ & 50 & 1.4 & 28 & 0 & 0 & 0 & 0 & 0 & 0 & 1 & 0 & 0 & 0 \\
\hline Didanosine $e^{12,16,69}$ & 400 & -0.8 & 1.2 & 0 & 0 & 0 & 1 & 0 & 0 & 0 & 0 & 0 & 0 \\
\hline Ethambutol $12,16,72$ & 1200 & 0.1 & $2-4$ & 0 & 0 & 0 & 0 & 1 & 1 & 0 & 0 & 0 & 0 \\
\hline Fluconazole 12,16 & 200 & 0.75 & 30 & 0 & 0 & 0 & 0 & 0 & 0 & 0 & 0 & 0 & 1 \\
\hline $\begin{array}{l}\text { Hydrocodone \& para- } \\
\text { cetamo|12,16,69,79,89,96 }\end{array}$ & 3000 & 0.7 & $1.3-3.8$ & 0 & 1 & 0 & 1 & 0 & 0 & 0 & 1 & 1 & 0 \\
\hline Indinavir $4,12,16,57,60$ & 2400 & 3.1 & 1.8 & 0 & 0 & 1 & 1 & 0 & 1 & 0 & 0 & 0 & 1 \\
\hline Isoniazid12,15,16,66,69,77 & 300 & -0.8 & 2.8 & 0 & 0 & 0 & 1 & 1 & 0 & 1 & 0 & 0 & 0 \\
\hline Josamycin 10,16,25,27,62,87 & 500 & 1.24 & & 0 & 0 & 1 & 1 & 0 & 1 & 0 & 0 & 0 & 0 \\
\hline Mercaptopurine ${ }^{12,16,68,88}$ & 200 & 0.4 & 1 & 0 & 1 & 0 & 1 & 0 & 1 & 0 & 0 & 0 & 0 \\
\hline Methotrexate $12,16,18,69$ & 2.5 & 0.1 & $3-15$ & 0 & 0 & 1 & 1 & 0 & 1 & 0 & 0 & 0 & 0 \\
\hline
\end{tabular}




\begin{tabular}{|c|c|c|c|c|c|c|c|c|c|c|c|c|c|}
\hline $\begin{array}{l}\text { Drug } \\
\text { High child report } \\
\text { frequency }\end{array}$ & $\begin{array}{l}\text { Daily } \\
\text { dose }\end{array}$ & $\log P$ & $\begin{array}{l}\text { Plasma } \\
\text { t1/2 (hrs) }\end{array}$ & BSEP & MRP & $\begin{array}{l}\text { Biliary } \\
\text { excr }\end{array}$ & $\begin{array}{l}\text { Mito } \\
\text { dysftn }\end{array}$ & HLA & $\begin{array}{l}\text { Hyper- } \\
\text { sens }\end{array}$ & $\begin{array}{l}\text { React } \\
\text { metab }\end{array}$ & $\begin{array}{l}\text { GSH } \\
\text { adduct }\end{array}$ & $\begin{array}{l}\text { Coval } \\
\text { bindg }\end{array}$ & MDI \\
\hline Minocycline ${ }^{12,16,69}$ & 200 & 0.4 & $11-22$ & 0 & 0 & 0 & 1 & 0 & 1 & 0 & 0 & 0 & 0 \\
\hline Nelfinavir $4,16,57,60$ & 2500 & 4.46 & $3.5-5$ & 0 & 0 & 1 & 1 & 0 & 1 & 0 & 0 & 0 & 1 \\
\hline Oxacillin 16,63,94,95 & 2000 & 1.9 & 0.5 & 0 & 0 & 1 & 0 & 0 & 1 & 0 & 0 & 0 & 0 \\
\hline Paracetamo|12,16,69,79,89,96 & 3000 & 0.7 & $1.2-3$ & 0 & 1 & 0 & 1 & 0 & 0 & 0 & 1 & 1 & 0 \\
\hline Pemoline ${ }^{12,16,54}$ & 40 & 1.3 & 12 & 0 & 0 & 0 & 0 & 0 & 1 & 0 & 0 & 0 & 0 \\
\hline Propylthiouracil12,16,41,69,95 & 100 & 1.6 & & 0 & 0 & 1 & 0 & 0 & 1 & 1 & 0 & 0 & 0 \\
\hline Pyrazinamide ${ }^{12,16,69}$ & 1500 & -1 & $9-10$ & 0 & 0 & 0 & 0 & 0 & 1 & 0 & 0 & 0 & 0 \\
\hline Rifampicin 12,16,18,60,69,77 & 600 & 1.4 & & 1 & 0 & 1 & 0 & 1 & 1 & 0 & 0 & 0 & 0 \\
\hline Ritonaviri2,16,57,60,89 & 1200 & 4.9 & & 1 & 1 & 1 & 0 & 0 & 1 & 0 & 0 & 1 & 1 \\
\hline Sulfasalazine 12,16,39 $^{-1}$ & 2000 & 2 & $10-15$ & 0 & 1 & 0 & 1 & 0 & 1 & 0 & 0 & 0 & 0 \\
\hline Valproic Acid $12,16,18,69,79$ & 1500 & 2.7 & $9-16$ & 0 & 0 & 0 & 1 & 0 & 1 & 1 & 0 & 1 & 0 \\
\hline Zidovudine $4,12,16,68,69,79$ & 600 & 0.1 & $0.5-3$ & 0 & 1 & 0 & 1 & 0 & 1 & 0 & 0 & 0 & 0 \\
\hline
\end{tabular}




\begin{tabular}{|c|c|c|c|c|c|c|c|c|c|c|c|c|c|}
\hline Drug & $\begin{array}{l}\text { Daily } \\
\text { dose }\end{array}$ & $\log P$ & $\begin{array}{l}\text { Plasma } \\
\mathrm{t} 1 / 2 \\
\text { (hrs) }\end{array}$ & BSEP & MRP & $\begin{array}{l}\text { Biliary } \\
\text { excr }\end{array}$ & $\begin{array}{l}\text { Mito } \\
\text { dysftn }\end{array}$ & HLA & $\begin{array}{l}\text { Hyper- } \\
\text { sens }\end{array}$ & $\begin{array}{l}\text { React } \\
\text { metab }\end{array}$ & $\begin{array}{l}\text { GSH } \\
\text { adduct }\end{array}$ & $\begin{array}{l}\text { Coval } \\
\text { bindg }\end{array}$ & $\mathrm{MDI}$ \\
\hline \multicolumn{14}{|l|}{ Higher reports in elderly } \\
\hline $\begin{array}{l}\text { Amoxicillin:clavu- } \\
\text { lanate }{ }^{10,16,22,60.79}\end{array}$ & 500 & 0.97 & $1-1.3$ & 0 & 0 & 0 & 0 & 1 & 1 & 0 & 1 & 0 & 0 \\
\hline Carbimazole ${ }^{10,16,23,53,67,79}$ & $5-20$ & 1.26 & & 0 & 0 & 1 & 0 & 0 & 1 & 0 & 1 & 0 & 1 \\
\hline Chlorpromazine 12,18,33,66, $69,95^{-1}$ & 100 & 4.7 & & 0 & 0 & 1 & 0 & 0 & 1 & 1 & 0 & 0 & 0 \\
\hline Cyproterone $10,16,44,53,69$ & $200-300$ & 3.41 & $45-95$ & 0 & 0 & 0 & 0 & 0 & 0 & 1 & 0 & 0 & 0 \\
\hline $\begin{array}{l}\text { Danazol12,16,60 } \\
\text { Flucloxacillin 11,10,16,17,53,60, }\end{array}$ & 600 & 4.9 & $10-24$ & 1 & 0 & 1 & 0 & 0 & 0 & 0 & 0 & 0 & 0 \\
\hline $69,90,95$ & 1000 & 2.57 & & 0 & 0 & 1 & 0 & 1 & 0 & 1 & 1 & 0 & 0 \\
\hline $\begin{array}{l}\text { Fusidic } \\
\text { acid7,10,16,17,53,60,69,90,95 }\end{array}$ & 1500 & 5.7 & & 1 & 1 & 1 & 0 & 0 & 1 & 0 & 0 & 0 & 0 \\
\hline $\begin{array}{l}\text { INH+Pyrazin.+ Rifampin }{ }^{12,15-} \\
\text { 18,66,69,77 }\end{array}$ & 300 & -0.8 & $2.8-10$ & 1 & 0 & 1 & 1 & 1 & 1 & 1 & 0 & 0 & 0 \\
\hline Nimesulide $6,12,16,78,92$ & 200 & 2.2 & $1.8-4.7$ & 0 & 1 & 0 & 1 & 0 & 0 & 1 & 0 & 1 & 0 \\
\hline Roxithromycin 10,14,16,40,71,95 & 300 & 3.07 & 10 & 0 & 0 & 1 & 0 & 0 & 1 & 0 & 0 & 0 & 0 \\
\hline
\end{tabular}

*clearance decreased in the elderly

Drug characteristics were summarized for those drugs with higher relative WHO liver event reporting in children, age 0-17 (portrayed in upper table) or the elderly (age 65 or higher). Profiled characteristics included daily drug dose, $\log \mathrm{P}$ (or lipophilicity; where $\log \mathrm{P}>3$ is associated with high lipophilicity and increased risk of toxicity), and drug plasma half-life in hours. Drug interaction with bile salt export pump (BSEP) or multidrug resistance associated proteins (MRP-2, -3 , and -4), biliary excretion, mitochondrial dysfunction, HLA marker(s) associated with toxicity, hypersensitivity, reactive metabolites, glutathione (GSH) adducts, covalent binding, or metabolism dependent inhibition (MDI) are presented as detected $=1$ or absent or unknown $=0$. The following categories were associated with missing data: HLA-associated toxicity, production of reactive metabolites, glutathione adducts, protein covalent binding and metabolism dependent inhibition. 


\section{Supplementary Table 1.}

\section{Liver Injury Type}

Hepatocellular injury

Cholestatic Injury

Hepatic failure

\section{Custom Preferred Search Terms}

'Acute hepatic failure', 'Alanine aminotransferase abnormal', 'Alanine aminotransferase increased', 'Aspartate aminotransferase abnormal', 'Aspartate aminotransferase increased', 'Blood bilirubin unconjugated increased', 'Cytolytic hepatitis', 'Hepatic enzyme abnormal', 'Hepatic enzyme increased', 'Hepatic failure', 'Hepatic function abnormal', 'Hepatic necrosis', 'Hepatitis', 'Hepatitis acute', 'Hepatitis fulminant', 'Hepatitis toxic', 'Hepatocellular damage', 'Hepatotoxicity', 'Jaundice hepatocellular', 'Liver function test abnormal', 'Liver injury',

'Mixed hepatocellular-cholestatic injury', 'Subacute hepatic failure', 'Transaminases abnormal',

'Transaminases increased'

'Mixed hepatocellular-cholestatic injury', 'Bilirubin conjugated increased', 'Bilirubin urine', 'Blood bilirubin abnormal', 'Blood bilirubin increased', 'Cholestasis', 'Hepatitis cholestatic', 'Hyperbilirubinaemia', 'Jaundice', 'Jaundice cholestatic', 'Urine bilirubin increased', 'Yellow skin'

'Coma hepatic', 'Hepatic encephalopathy', 'Hepatic failure', 'Hepatic necrosis', 'Hepatitis fulminant', 'Liver transplant' 


\section{Reflection on how leadership learnings helped to impact the study problems}

The key leadership values, which helped me to address the study problems, include passion for my work, teamwork with highly motivated collaborators, shared goals and vision, respect and affection for my diverse team members, and empowerment of team members. I have had the privilege of working with our highperforming project team members on prior drug safety projects. With our team's deep expertise in epidemiology, data mining, statistics, and liver injury, my vision was to seek unifying mechanisms of aging-related toxicity differences, which could inform clinicians, regulators, and drug developers.

My key leadership strengths are strategic vision, or ability to "see the big picture", innovative ideas, flexible persistence, and ability to engage others in rapid change (as indicated by my strong originator scores on the Change Style Indicator Test, and the Gallup Organization's Strength Finders 2.0). Through testing more than a million people, the Gallup Organization's survey reliably identifies a person's top 5 strengths. Then, through maximizing your strengths, you can enjoy greater success and pleasure in your work. My strengths align with my personality type as an extrovert, intuitive, thinker, and judge (on Myers-Briggs Type Indicator). As most people do not seek change or new ideas, I have frequently found myself impatiently waiting for others to "see" the value and scope of new ideas, to realize our shared vision.

I now recognize that I can partner with other talented people with similar focus to achieve our goals, by enabling each team member to work to their strengths. As demonstrated in the evidence-based data of Jim Collins' Good to Great, truly great 
teamwork happens when you get talented, disciplined, diverse people working together towards an inspiring goal. By letting people innovate together, freely sharing ideas and capitalizing on their talents, you can achieve anything. I've had the great pleasure to work with high-performing team members who are self-motivated innovators, with whom I've established trust and respect, to rapidly achieve results (as accomplished in this project). In broader groups, l've also realized that presenting ideas and strategies in a more detailed fashion assures that diverse colleagues all understand and can thereby further contribute to our team ideas. So, l've worked to be more deliberate in my reasoning, which is of particular value when sharing ideas and results outside our team.

To ensure public health success, there's a pressing need to develop women leaders and expand leadership diversity. So, I brought together productive female colleagues with diverse talents to discuss the issue, our resources, and each person's level of interest in the project. We agreed that pediatric data were very limited. Heide Stirnadel is an epidemiologist with a longstanding interest in hepatotoxicity, having collaborated with the CDC on the toxicity of anti-tuberculosis medications. Heide identified clinical study data in over 9000 children, which would be of high value to understand pediatric safety. She expressed a keen interest in examining this data, and was somewhat hindered by limited resource. So, we identified interested statistical colleagues, discussed with FDA and EU regulators to confirm a high level of regulatory interest, and I met with Heide's management to share the high value of this research. Our collaborative input enabled Heide's analysis. I nominated Heide to share her data at an FDA national meeting, where she gave an excellent presentation and met with senior academicians and FDA colleagues to advance her work. 
Ayako Suzuki's a highly creative translational physician scientist of international renown, with deep expertise in hepatology, epidemiology and statistics. Nancy Yuen's a talented drug safety expert, data miner and pharmacist. Together, Ayako and Nancy have developed innovative data mining approaches to examine large datasets to develop new hypotheses. I recognized that their unique expertise would greatly expand our understanding of drug toxicity with aging, and nicely complement Heide's epidemiology and toxicity expertise. So, I asked their interest in collaborating on drug toxicity with aging. I personally contributed my passion for patient safety, curiosity in understanding liver injury, and resolve to achieve our goal.

Our mutual respect, work ethic, friendship, and interests have made Ayako, Nancy, Heide and I successful long-term collaborators. Together, we were united by a clear common goal, maximized our quite different skills to develop a protocol, complete the data mining analysis, and achieve a high quality product. Our team of women is diverse \& productive: age 30-50's, of differing backgrounds, personalities, expertise, career stage, and approaches.

In my team leadership, l've encouraged a broad range of views and approaches with emphasis on innovation, a high level of respect of all team members, good listening skills, evidence-based assessment, excellence in execution, and emphasized recognition of team members for their contributions. I've enjoyed mentoring, and empowering team members to lead analyses and studies in their area of expertise, which has resulted in their career advancement and broad global opportunities and collaborations for our team. 
My future leadership goals include collaboratively developing automated diagnostic tools using electronic health records with global colleagues and building automated clinician-friendly systems for health prevention activities in US health systems. These goals will enable me to use my key strengths: collaborative leadership, strategic vision and ideas. Simultaneously, I seek to achieve my goal of becoming an excellent public health leader, which I define as a leader who innovates to improve health broadly, shares and adapts their vision to unite others in productive collaborations to achieve their mutual goal, is energizing and catalyzes new ideas, communicates and listens well, encourages questions and reasoned conflict, inspires others to excellence, seeks team diversity and challenge, applauds team members' efforts and progress, supports team members in their personal development and goals, and creates a fun and engaging environment where all can excel.

\section{References}

Collins, James Charles. Good to great and the social sectors: A monograph to accompany good to great. Harper Collins, 2005.

Collins, Jim. Good to great: Why some companies make the leap... and others don't. Harper Collins, 2001.

Rath, Tom. Strengths Finder 2.0. New York, NY: Gallup Press, 2007. 